\title{
Pengembangan Media Pembelajaran Video Interaktif untuk Meningkatkan Hasil Belajar IPA Siswa Sekolah Dasar
}

Received:

$8 / 12 / 2021$

Accepted:

$15 / 12 / 2021$

Published:

$31 / 12 / 2021$

\author{
${ }^{1}$ Rina Rahmawati, ${ }^{2}$ Khaeruddin ${ }^{3}$ Amri Amal \\ Universitas Muhammadiyah Makassar, Makassar, Indonesia \\ *3amriamal@unismuh.ac.id
}

\begin{abstract}
This study aimed to find out how interactive video learning media can improve science learning outcomes in grade $\mathrm{V}$ in elementary school. Types of Research and Development (research and development) with reference to the 5 steps developed using the ADDIE model. The subjects in this study were the fifth-grade students of SD Negeri 60 Moncongloe Lappara, totaling 14 people. The instrument used is a media validation questionnaire sheet for experts (lecturers and teachers) and student response. Data collection techniques used were observation, questionnaires, learning outcomes tests. The results showed that the interactive video learning media obtained a media validity percentage by 2 expert validators with a final score of $95.8 \%$ in the "Very Valid" category. Assessment of student responses in field trials showed very good results that students strongly "Strongly Agree". In the test for improving learning outcomes using $t$ _count $(8,339)>t$ _table $(2,160)$ and in the gain test, the results show the weak category of $7 \%$, medium as much as $79 \%$, and high category of $14 \%$, from the results of the test to improve learning outcomes that have been carried out, it is proven that there are improvement of learning outcomes by using interactive video learning media which means it is effective to be applied in learning.
\end{abstract}

Keywords: Development, Interactive Video, Science

\begin{abstract}
Abstrak
Tujuan dari penelitian ini adalah untuk mengetahui bagaimana Media Pembelajaran Video Interaktif dapat meningkatkan hasil belajar IPA pada kelas V disekolah dasar. Jenis Penelitian Pengembangan (research and development) dengan mengacu pada 5 langkah yang dikembangkan dengan menggunakan model ADDIE. Adapun subjek di dalam penelitian ini adalah siswa kelas V SD Negeri 60 Moncongloe Lappara yang berjumlah 14 orang. Instrument yang digunakan berupa lembar angket validasi media untuk para ahli (dosen dan guru), lembar angket respon siswa. teknik pengumpulan data yang digunakan observasi, Angket, Tes Hasil Belajar. Hasil penelitian menunjukkan bahwa media pembelajaran video interaktif memperoleh persentasi kevalidan media oleh 2 validator ahli dengan nilai akhir sebesar 95,8\% dengan kategori "Sangat Valid". Penilaian respon peserta didik pada ujicoba lapangan menunjukkan hasil yang sangat baik bahwa siswa sangat "Sangat Setuju". Pada uji peningkatan hasil belajar dengan menggunakan $t_{\text {hitung }}(8.339)>t_{\text {tabel }}(2.160)$ dan pada uji gain menunjukkan hasi kategori lemah $7 \%$, sedang sebanyak 79\%, dan kategori tinggi 14\%, dari hasil uji peningkatan hasil belajar yang telah dilakukan yaitu dibuktikan terdapat peningkatan hasil belajar dengan menggunakan media pembelajaran video interaktif yang artinya efektif untuk diterapkan di dalam pembelajaran.

Kata kunci: IPA, Pengembangan, Video Interaktif
\end{abstract}




\section{0 | Rina Rahmawati, Khaeruddin, Amri Amal}

\section{Pendahuluan}

Pendidikan merupakan memperbaiki pengalaman, nilai-nilai, kognitif, dan psikomotorik pada generasi muda yang akan datang sebagai usaha generasi sekarang dalam mempersiapkan tujuan hidup generasi selanjutnya, baik jasmani maupun rohani. Dengan pendidikan sesesorang dibekali dengan berbagai pengetahuan, keahlian, keterampilan dan juga pentingnya berbagai macam tatanan hidup baik yang berupa norma-norma, aturan yang positif, hal penting dalam proses pendidikan ialah pengusaan konsep dalm suatu pembelajaran, pembelajaran akan berjalan baik apabila dalam proses pembelajaran pendidik dapat mengaplikasikan salah satu prinsip menyampaikan penyampaian pembelajaran yaitu menarik perhatian siswa.

Menurut Ibrahim sebagaimana telah dikutip oleh (Daryanto, 2013) yang menyatakan bahwa dalam era perkembangan ilmu pengetahuan dan teknologi yang sangat pesat seperti sekarang, profesionalisme guru dituntut harus mampu dalam mengelola berbagai informasi yang didapat dan lingkungan dalam memfasilitasi proses kegiatan belajar peserta didik. Pendidik dan peserta didik merupakan pelaku terlaksananya tujuan pembelajaran dan tujuan pembelajran ini akan mencapai hasil maksimal apabila proses pembelajran berjalan efektif.

Dalam pembelajaran guru dituntut mampu menciptakan situasi pembelajaran yang aktif khususnya pembelajaran IPA. Keikutsertaan peserta didik dalam mengikuti pembelajaran ilmu pengetahuan alam sangat penting karena pada pembelajaran ilmu pengetahuan alam memberikan ruang untuk mengembangkan wawasan, keterampilan, dan memanfaatkan berbagai jenis teknologi yang bisa diterapkan dalam kehidupan sehari-hari (Hisbullah \& Firman, 2019; Wiratman et al., 2019). Dalam pembelajaran ipa, perangkat dalam pembelajaran yang diciptakan sebaiknya harus meningkatkan kemampuan berpikir kritis siswa, khususnya mata pelajaran IPA. Media pembelajaran yang dibutuhkan, perlu didesain dengan perancangan yang tepat karena media pembelajaran yang interaktif tidak pernah digunakan oleh pendidik didalam kelas.

Tujuan dari pembelajaran IPA mengarahkan dan membentuk kemampuan pada diri peserta didik untuk berfikir kritis, analitis, sistematis, dan kreatif dan untuk memahami beberapa konsep dalam materi IPA yang membutuhkan pemahaman tertentu, sehingga sulit dipahami oleh peserta didik secara langsung karena banyaknya istilah-istilah asing (Anggareni et al., 2013; Winarso, 2014). Dalam proses pembelajaran yang dikembangkan memerlukan proses kesabaran dalam menunggu respon siswa yang belum terbiasa pada proses pembelajaran yang dikembangkan. Berdasarkan observasi yang dilakukan pada siswa di kelas V SDN 60 Moncongloe Lappara, pada proses penyampaikan materi pembelajaran guru menyampaikan materi pembelajaran hanya menggunakan media papan tulis dan juga buku paket yang ada didalam kelas. Guru cenderung menggunakan media yang kurang dalam menunjang keaktifan siswa sehingga siswa kurang aktif dalam proses pembelajaran, sehingga hasil belajar murid kurang mengalami peningkatan. 
Berdasarkan uraian masalah diatas, diperlukan adanya suatu media pembelajaran yang dapat meingkatkan hasil belajar dan menarik perhatian dan bersifat interaktif agar siswa lebih tertarik dan mudah memahami pembelajaran. Hal ini sesuai dengan pernyataan yang disampaikan oleh (Paseleng \& Arfiyani, 2015) bahwa perangkat pembelajaran yang dihadirkan perlu sebaiknya mampu meningkatkan kemampuan berpikir kritis peserta didik, khususnya pada mata pelajaran IPA. Dalam hal ini dibutuhkannya Media pembelajaran yang interaktif belum pernah digunakan oleh guru kelas. Selain itu, media pembelajaran yang dikembangkan harus disesuaikan dengan karakteristik peserta didik kelas V di SDN 60 Moncongloe Lappara. Meskipun waktu yang diperlukan untuk mengembangkan media pembelajaran jenis ini cukup lama, namun diharapkan media pembelajaran ini dapat membantu peserta didik untuk lebih mudah memahami materi sistem gerak hewan dan manusia membuat mereka menjadi lebih aktif jika dibandingkan ketika guru menggunakan media pembelajaran berupa gambar saja yang ada didalam buku paket.

Salah satu media yang dapat meningkatkan hasil belajar dan minat siswa, serta melibatkan mereka secara aktif di dalam mempelajari materi sistem gerak hewan dan manusia adalah media pembelajaran berupa video interaktif yang dibuat menggunakan aplikasi yang bisa diedit atau dibuat di handphone yaitu aplikasi CapCut, Canva dan Inshot (Arif \& Iskandar, 2018). Pemilihan CapCut, Canva dan Inshot sebagai salah satu aplikasi yang digunakan untuk membuat video interaktif aplikasi ini digunakan karna mempermudah dalam pembuatan video karna dapat diedit dihandphone, di edit dimanasaja, diaplikasi ini jg terdapat berbagai berbagai tema yang menarik untuk didesain untuk membuat video pembelajaran.

Media video pembelajaran merupakan seperangkat komponen atau media yang mampu menampilkan gambar sekaligus suara dalam waktu bersaman (Asyhar, 2012; Marhaeni et al., 2020). Media Video interaktif merupakan media yang didalamnya menggabungkan berbagai teks, gambar, suara, gerak ataupun animasi yang bersifat interaktif dalam menghubungkan media pembelajaran tersebut dalam penggunaannya (Octaviani, 2017). Suatu media pembelajaran dapat dikatakan interaktif apabila terjadi keterlibatan antara peserta didik dengan media tersebut, sehingga peserta didik tidak hanya sekedar melihat atau mendengarkan materi didalam media. Salah satu hal yang penting dalam video interaktif adalah yaitu alat atau sarana yang digunakan dalam membuat media yaitu handphone, untuk pembuatan media video yang akan dikembangkan.

Media juga memiliki manfaat terhadap pembelajaran individu yaitu kedudukan seluruhnya melayani kebutuhan belajar peserta didik, sehingga media yang digunakan dalam pembelajaran harus efesien dan efektif dan dapat sesuai dengan kebutuhan peserta didik (Karo-Karo \& Rohani, 2018). Media pembelajaran yang sesuai dengan kebutuhan peserta didik yaitu media pembelajaran berbasis teknologi, yaitu seperti media pembelajaran berupa video interaktif yakni gambar animasi bergerak yang menarik dan simulasi audiovisual untuk menarik keaktifan dan minat belajar siswa 


\section{2 | Rina Rahmawati, Khaeruddin, Amri Amal}

terhadap materi pembelajran yang diajarkan guru, media pembelajaran video interaktif lebih menekankan pada konsep yang kontekstual.

Berdasarkan uraian di atas, maka penulis tertarik untuk mengembangakan media pembelajaran video interaktif pada materi sistem gerak hewan dan manusia yang disesuaikan dengan Kurikulum 2013 yang saat ini diterapkan di SD Negeri 60 Moncongloe Lappara Kecamatan Moncongloe, sehngga diharapkan media video interaktif ini bisa mempermuda siswa dalam memahami materi pembelajaran yang diberikan dan siswa dapat aktif dalam proses pembelajaran sehingga dapat meningkatkan hasil belajar siswa.

\section{Metode Penelitian}

Metode yang digunakan di dalam penelitian ini adalah penelitian dan pengembangan atau Research and Development (R\&D). Penelitian dan pengembangan atau R\&D (Research and Development) merupakan metode penelitian yang bertujuan untuk menghasilkan suatu produk tertentu, kemudian menguji keefektifitasannya (Sugiyono, 2017). Video interaktif sebagai produk yang dihasilkan, dikembangkan dengan model desain ADDIE. Adapun langkah-langkah model ADDIE adalah: (1) tahap analisis; (2) tahap desain; (3) tahap pengembangan; (4) tahap implementasi; (5) tahap evaluasi.

Pengembangan media pembelajaran berupa video interaktif ini dilakukan dengan serangkaian kegiatan uji coba yang meliputi: ujicoba ahli, ujicoba lapangan. Adapun subjek di dalam penelitian ini adalah ahli media (dosen dan guru kelas) dan peserta didik kelas V SD Negeri 60 Moncongloe Lappara. Teknik pengumpulan data yang digunakan adalah observasi, penyebaran angket, dan Tes Hasil Belajar. Instrumen pengumpulan data yang digunakan meliputi: angket respon peserta didik dan angket penilaian para ahli.

Penelitian ini menggunakan teknik analisis data berupa uji validitas produk, uji respon siswa, dan perhitungan peningkatan hasil belajar. Data uji validitas produk diperoleh dari hasil penilaian para ahli. Tujuan dari uji validitas produk ini adalah untuk mengukur valid atau tidaknya media pembelajaran yang dikembangkan. Untuk mengukur validitas media pembelajaran ini, digunakan rumus (Purwanto, 2013:102):

Keterangan :

$$
\mathrm{NP}=\frac{R}{S M} \times 100 \%
$$

$\begin{array}{ll}\mathrm{NP} & =\text { Nilai Persentase Kelayakaan } \\ \mathrm{R} & =\text { Jumlah Skor yang diperoleh } \\ \mathrm{SM} & =\text { Jumlah skor Maksimal } \\ 100 \% & =\text { Bilangan Tetap }\end{array}$

Mengukur hasil belajar siswa menggunakan rumus uji $t$ dan uji gain yang dijelaskan oleh Sugiyono (2017:148) sebagai berikut: 
Keterangan:

$$
\mathrm{t}=\frac{M d}{\sqrt{\frac{\sum x^{2} d}{N_{2} N_{1}}}}
$$

Md : Mean dari perbedaan pre-test dan posttest

d : Deviasi Maisng-masing subjek

$\sum x^{2} d \quad$ : Jumlah kuadrat deviasi

$N \quad$ :Subjek pada sampel

$$
\text { Gain }(G)=\frac{\text { Skor posttest }- \text { Skor pretest }}{\text { Skor maksimum - Skor pretest }}
$$

\section{Hasil dan Pembahasan}

Media pembelajaran video interaktif merupakan media pembelajaran yang didalamnnya menggabungkan berbagai unsur teks, suara, gambar bergerak ataupun grafik yang bersifat interaktif untuk menghubungkan media pembelajaran tersebut dalam penggunaannya. Video interaktif pada pembelajaran IPA dikelas V pada materi system geak hewan dan untuk kelas V SD Negeri 60 Moncongloe Lappara. Media Pembelajaran Video Interaktif yang dikembangkan dibuat dengan menggunakan aplikasi dihandphone aplikasi CapCut, Canva dan Inshot. Aplikasi CapCut, Canva dan Inshot digunakan untuk membuat gambar animasi bergerak interaktif animasi kartun.

Keunggulan produk video interaktif ini adalah: (1) siswa dapat aktif dalam proses pembelajaran, (2) siswa tidak mudah bosan, (3) adanya animasi kartun bergerak yang dapat menarik minat siswa saat menonton, (4) penjelasan dalam video dibuat dengan bahasa yang mudah dimengerti siswa, (5) penjelasan materi dirangkung dengan dengan padat tetapi mugah dimengerti siswa, (6) dan pembuatan video bisa dilakukan melalui aplikasi dihand phone. Adapun komponenkomponen di dalam video interaktif yang dikembangkan secara lebih rinci diuraikan sebagai berikut.
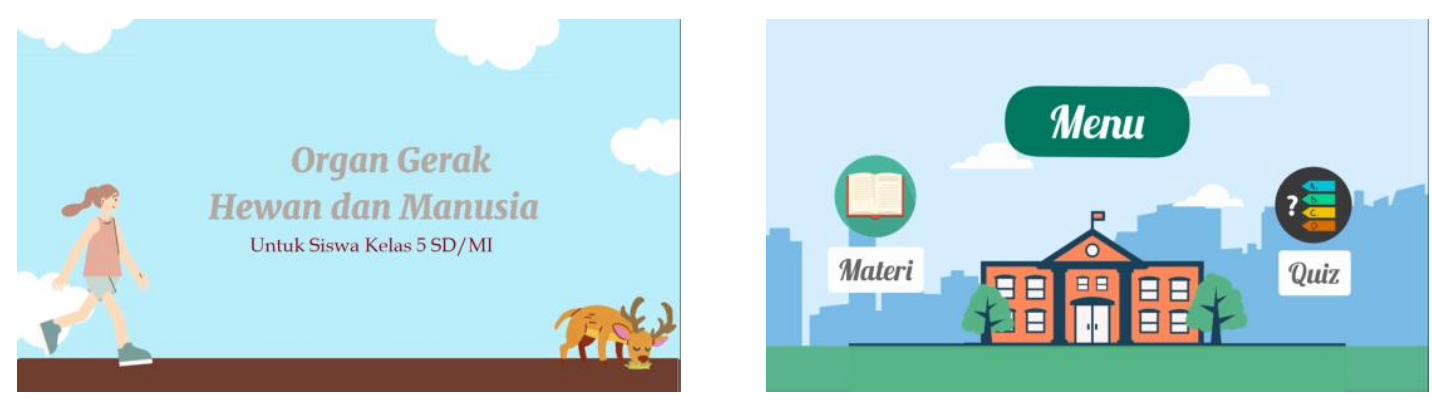

Gambar 1 Halaman Awal Media 

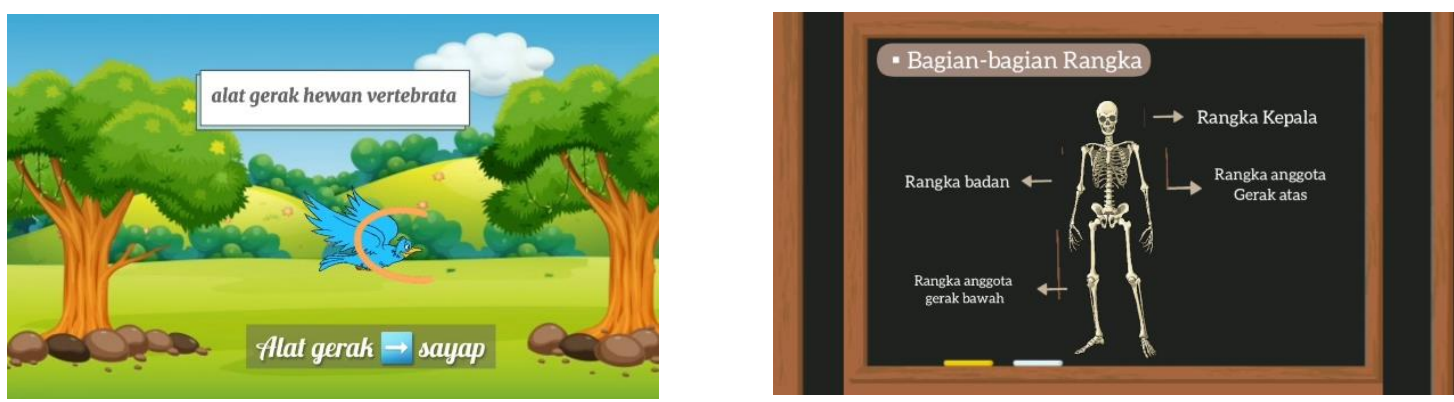

Gambar 2 Halaman isi video

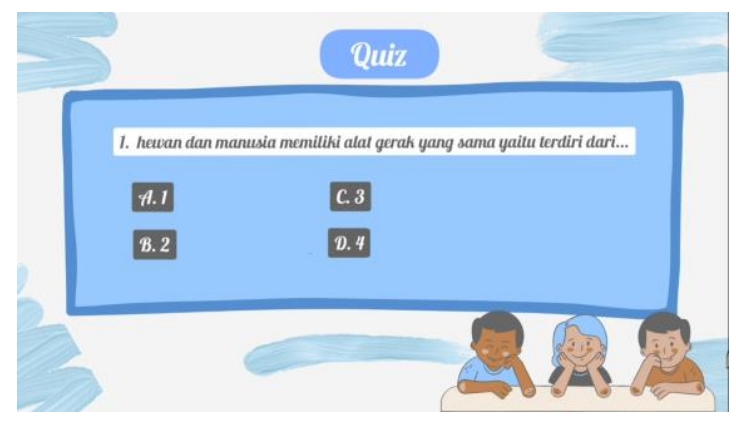

Gambar 3 Halaman Quiz

Berdasarkan hasil validasi ahli yang telah tersaji ialah hasil penelitian ahli terhadap produk media pembelajaran video interaktif yang dikembangkan. Penilaian ini disajikan bisa dapat dilihat sejauh mana kevalidan produk yang telah dikembangkan. Akumulasi persentasi Pertama, Aspek penilaian materi menujukkan yakni skor rata-rata diperoleh sebesar 4 dengan persentase $100 \%$. Apabila dilihat dari kategori penilaian sudah ada yaitu uji kevalidan media dijelaskan pada bagian sebelumnya skor rata-rata termasuk kedalam kategori "Sangat Valid". Kedua, penilaian aspek media menunjukkan skor rata-rata yang diperoleh sebesar 3.5 dengan persentase $87.5 \%$. Apabila dilihat dari kategori penilaian yang sudah ada yaitu uji kevalidan media dijelaskan pada bagian sebelumnya skor rata-rata termasuk kedalam kategori "Sangat Valid". Ketiga, penilaian aspek bahasa menunjukkan skor rata-rata diperoleh sebesar 3.8 dengan persentase 95.8\%. Apabila dilihat dari kategori penilaian yang sudah ada yaitu uji kevalidan media dijelaskan pada bagian sebelumnya skor rata-rata tersebut termasuk dalam kategori "Sangat Valid".

Hasil penilaian ahli menyatakan bahwa produk media dapat digunakan dengan revisi yang kecil. Kemudian produk yang sudah direvisi kemudian dikembangkan pada beberapa komponen yang ada didalam video yang perlu diperbaiki, seperti perubahan atau penambahan tujuan terkait materi dalam video dan juga memperbaiki font dalam video agar dapt lebih mudah siswa dalam membaca, dan intonasi suara supaya lebih ditingkatkan. 
Respon siswa terhadap media pembelajaran video interaktif mendapatkan hasil respon yang baik yaitu kategori "sangat setuju". Pada tahap ini siswa telah menyatakan bahwa produk yang dikembangkankan sudah baik dan mudah dipahami. Pengembangan Media Pembelajaran Video Interaktif IPA yang telah dikembangkan berdasarkan penelitian memiliki efektifitas yang baik untuk diterapkan didalam pembelajaran hal ini dapat dibuktikan dengan uji t dengan rumus Sugiyono (2017:148), didapatkan hasil bahwa nilai $t_{H i t u n g}>t_{\text {tabel }}$ yakni 8.399 > 2.160, maka $\mathrm{H}_{0}$ ditolak dan $\mathrm{H}_{a}$ diterima. Artinya dengan demikian, dapat dikatakan bahwa media pembelajaran video interaktif memiliki efektifitas yang baik dan dapat meningkatkan hasil belajar siswa kelas V di Sekolah Dasar.

Berdasarkan data hasil perhitungan menggunakan pada analisis uji Gain (G) didapatkan hasil nilai skor siswa yang mengalami peningkatan dengan kategori lemah sebanyak 1 siswa dipersentase sebesar $7 \%$, siswa yang mengalami peningkatan dengan kategori sedang sebanyak 11 siswa dengan persentase 79\%, dan siswa yang mengalami peningkatan dengan kategori tinggi sebanyak 2 siswa dengan persentase 14\%. Dengan demikian pada uji gain dibuktikan dengan adanya peningkatan pada hasil belajar siswa dengan menggunakan " Media Pembelajaran Video Interaktif IPA dengan materi "Organ Gerak Hewan dan Manusia" dan dibuktikan pada uji-t dan uji gain didapatkan hasil bahwa produk media yang dikembangkan dapat meningkatkan hasil belajar siswa pada pembelajaran IPA di Sekolah Dasar.

\section{Kesimpulan}

Berdasarkan hasil penelitian dan pembahasan maka dapat disimpulkan: Penelitian ini merupakan jenis penelitian dan pengembangan (Research and Development) dengan menggunakan model pengembangan ADDIE. Model pengembangan ini terdiri dari lima langkah yang sistematis. Adapun langkahlangkah model ADDIE adalah: (1) tahap analisis; (2) tahap desain; (3) tahap pengembangan; (4) tahap implementasi; (5) tahap evaluasi. Adapun karakteristik Media Pembelajaran Video Interaktif yaitu media pembelajaran yang didalamnnya mengkombinasikan berbagai gambar, gerak, suara, grafik dalam waktu bersamaan yang bersifat interaktif sehingga dapat menarik minat penerima informasi dalam pembelajaran dalam penggunaannya media pembelajaran video interaktif didalamnnya menyediakan materi dengan berbagai ilustrasi visual dan audio dan berbagai gambar animasi menarik sehingga diharapkan untuk lebih mudah dipahami. Media pembelajaran video interaktif yang dikembangkan valid dan juga dapat meningkatkan hasil belajar siswa pada pembelajaran IPA di Sekolah. Hal ini dibuktikan dengan hasil uji t yang menunjukkan bahwa thitung $>$ ttabel dan uji gain didapatkan hasil terdapat peningkatan pada hasil belajar siswa dengan menggunakan "Media Pembelajaran Video Interaktif IPA dengan materi “Organ Gerak Hewan dan Manusia" sehingga sangat baik dan efektif diterapkan pada pembelajaran di Sekolah Dasar, sehingga dapat meningkatkan hasil belajar. 


\section{6 | Rina Rahmawati, Khaeruddin, Amri Amal}

Berdasarkan hasil penelitian pengembangan "Pengembangan Media Pembelajaran Video Interaktif IPA" materi "Organ Gerak Hewan dan Manusia" dapat diberi saran sebagai berikut. 1) Materi pada Media Pembelajaran Video Interaktif IPA bisa berkembang secara meluas dengan ditambahkan indikator yang berbeda. 2) Dalam penelitian ini lamanya waktu yang diperlukan dalam pengembangan alangkah baikknya dapat diperpanjang, dari fase analisis hingga fase evaluasi media pembelajaran supaya media yang dikembangkan mendapatkan hasil yang lebih maksimal.

\section{Referensi}

Amal, Amri dkk. 2013. “Pengembangan Model Pembelajaran Predict, Observe, Discuss, Dan Explain (Pode) Untuk Meningkatkan Hasil Belajar IPA Sekolah Dasar". (Online) Jurnal Ilmiah Pendidikan \& Pembelajaran. https://journal.unnes.ac.id/sju/index.php/jpe/article/view/3067

Anggareni, N. W., Ristiati, N. P., \& Widiyanti, N. L. P. M. (2013). IMPLEMENTASI STRATEGI PEMBELAJARAN INKUIRI TERHADAP KEMAMPUAN BERPIKIR KRITIS DAN PEMAHAMAN KONSEP IPA SISWA SMP. Jurnal Pendidikan Dan Pembelajaran IPA Indonesia, 3(1). https://ejournalpasca.undiksha.ac.id/index.php/jurnal_ipa/article/view/752

Arif, T. A., \& Iskandar, I. (2018). TEKNIK PENYUSUNAN BAHAN AJAR BAHASA INDONESIA BAGI GURU DI SEKOLAH DASAR. Prosiding Seminar Nasional Pendidikan, 1(1). https://jurnal.umj.ac.id/index.php/SNP/article/view/2802

Daryanto, D. (2013). Media Pembelajaran Peranannya Sangat Penting Dalam Mencapai Tujuan Pembelajaran. Yogyakarta: Gava Media.

Hisbullah, H., \& Firman, F. (2019). Penerapan Model Pembelajaran Snowball Throwing dalam Meningkatkan Hasil Belajar Ilmu Pengetahuan Alam di Sekolah Dasar. Cokroaminoto Journal of Primary Education, 2(2), 100-113. https:// doi.org/10.30605/CJPE.222019.231

Karo-Karo, I. R., \& Rohani, R. (2018). MANFAAT MEDIA DALAM PEMBELAJARAN. AXIOM: Jurnal Pendidikan Dan Matematika, 7(1). https://doi.org/10.30821/AXIOM.V7I1.1778

Marhaeni, S., Syamsuri, A. S., \& Arif, T. A. (2020). Pengaruh Penggunaan Metode Konvensional Berbantuan Media Gambar Terhadap Kemampuan Berbicara Siswa Kelas IV Sekolah Dasar di Kota Makassar. Syntax Literate; Jurnal Ilmiah Indonesia, 5(6), 192-201. https://doi.org/10.36418/SYNTAXLITERATE.V5I6.1334

Octaviani, S. (2017). PENGEMBANGAN BAHAN AJAR TEMATIK DALAM IMPLEMENTASI KURIKULUM 2013 KELAS 1 SEKOLAH DASAR. EduHumaniora | Jurnal Pendidikan Dasar Kampus Cibiru, 9(2), 93-98. https:// doi.org/10.17509/EH.V9I2.7039

Paseleng, M. C., \& Arfiyani, R. (2015). Pengimplementasian Media Pembelajaran Berbasis Multimedia Interaktif pada Mata Pelajaran Matematika di Sekolah Dasar. 
Scholaria: Jurnal Pendidikan Dan Kebudayaan, 5(2), 131-149. https:// doi.org/10.24246/J.SCHOLARIA.2015.V5.I2.P131-149

Purwanto. 2014. Evaluasi Hasil Belajar. Yogyakarta: Pustaka Pelajar.

Sugiyono. (2017). Metode Penelitian Kuantitatif, Kualitatif, dan RED. Bandung : Alfabeta.

Winarso, W. (2014). Membangun Kemampuan Berfikir Matematika Tingkat Tinggi Melalui Pendekatan Induktif, Deduktif Dan Induktif-Deduktif Dalam Pembelajaran Matematika. Eduma: Mathematics Education Learning and Teaching, 3(2), 56259. https://doi.org/10.24235/eduma.v3i2.58

Wiratman, A., Mustaji, M., \& Widodo, W. (2019). The effect of activity sheet based on outdoor learning on student's science process skills. Journal of Physics: Conference Series, 1157(2), 022007. https:// doi.org/10.1088/1742-6596/1157/2/022007 
38 | Rina Rahmawati, Khaeruddin, Amri Amal

--- Halaman ini sengaja di kosongkan ---

JUDIKDAS: Jurnal Ilmu Pendidikan Dasar Indonesia Volume 1 - No. 1 